\title{
Memória e ritmos temporais: o pluralismo coerente da duração no interior das dinâmicas da cultura urbano-contemporânea
}

\author{
Memory and time rhythms: \\ the coherent pluralism of duration into the \\ dynamics of urban-contemporary culture
}

Ana Luiza Carvalho da Rocha e Cornelia Eckert

Em sua célebre obra $A$ dialética da duração, Gaston Bachelard (1989a) postula uma prudência metodológica para o estudo da memória e nos mostra o caminho da noção de ritmo como noção temporal fundamental. Diante de questionamentos que compõem o debate sobre a complexidade da vida em um pluralismo de durações - do passado, o que permanece? O que dura? - assim responde o autor: "Apenas aquilo que tem razões para recomeçar" (Bachelard, 1989a: 8). O

\footnotetext{
Ana Luiza Carvalho da Rocha é antropóloga da UFRGS e professora convidada do PPGAS/UFSC (anarocha.ez@terra.com.br). Cornelia Eckert é professora do PPGAS/UFRGS (corneliaeckert@terra. com.br). Ambas as autoras são pesquisadoras do CNPq e coordenam o Projeto Banco de Imagens e Efeitos Visuais (Laboratório de Antropologia Social/UFRGS), com sede no ILEA/UFRGS.

Artigo recebido em 23 de dezembro de 2008 e aprovado para publicação em 4 de março de 2009.
}

Estudos Históricos, Rio de Janeiro, vol. 23, n 43, janeiro-junho de 2009, p. 105-124. 
enigma das representações do tempo é apreendido enquanto reordenação dos tempos vividos, contendo as descontinuidades e rupturas que acabam por engendrar uma representação das referências socioculturais, históricas e simbólicas que pontuam a ritmicidade de um cotidiano sempre reinventado.

Com tal pressuposto, nossa meta neste artigo é problematizar a memória no contexto das sociedades complexas. Nas cidades modernas - lócus investigados como favoráveis à amnése coletiva -, é sobretudo na cadência das interações e nas reverberações das relações de sociabilidade que a memória coletiva, enunciada por Maurice Halbwachs (1950), é inscrita. Da força dos sentidos das variações das formas sociais, perscruta-se na espessura das memórias geracionais a construção de uma reordenação de temporalidades narradas e performatizadas pelos citadinos como referentes aos arranjos de interações. Assim, é nessa cadência que os indivíduos e grupos "ritmam" uma "hierarquia de instantes" (Bachelard, 1989a: 25).

Se o estudo das sociedades complexas trouxe problemas para a matriz disciplinar da antropologia, tendo em vista uma tradição de pesquisa e de estudos criada a partir de uma experiência com sociedades simples (de pequena escala e cultura, relativamente homogênea), ele certamente contribuiu para ampliar seus recursos metodológicos na análise das sociedades/culturas humanas. A noção de "sociedades complexas" empregada pela comunidade científica - embora preserve os traços de sua matriz sociológica de origem - também expressa uma preocupação eminentemente antropológica com a heterogeneidade cultural, que deve ser entendida pela ótica da coexistência, conflituosa ou não, no mundo contemporâneo, de uma pluralidade de tradições cujas bases procedem da determinação das práticas e da idealização de valores dominantes.

Nesse ponto, a antropologia contemporânea brasileira tem apontado para o fato de que, nas modernas sociedades industriais, encontram-se sobrepostas diferentes estruturas espaço-temporais que reúnem, a um só tempo, tanto dimensões e instâncias desindividualizadoras quanto processos de individualização, estes vinculados a contextos socioculturais específicos, aos quais foram acomodados no fluxo do tempo, na memória e no patrimônio de seu corpo coletivo.

Gilberto Velho (1981) - na linha dos estudos de Ruth Cardoso e Eunice R. Durham sobre industrialização, urbanização e as migrações nos grandes centros urbanos do Brasil contemporâneo ${ }^{1}$-, foi um dos primeiros antropólogos a chamar a atenção para esse fenômeno temporal nas sociedades complexas (Velho, 1973, 1981 $)^{2}$ ao indicar, no caso das grandes metrópoles brasileiras, a presença da permanente contradição entre as particularizações de experiências de certos segmentos, categorias, grupos e indivíduos, e a universalização de outras experiências que se expressam culturalmente através de conjuntos de símbolos homogeneizadores. 
Ao reconhecer que nas modernas sociedades complexas a construção de identidades e a elaboração de projetos sociais se constituem dentro de um contexto em que diferentes "mundos" da vida social se interpenetram, os antropólogos urbanos, no Brasil, nos convidam a pensar a experiência de vida nas grandes metrópoles nos moldes dos estudos sobre memória e patrimônio desde as formas de sociabilidade, das trajetórias sociais, dos itinerários urbanos e do cotidiano dos habitantes. Mais ainda, nos desafiam a abandonar a perspectiva de que tais fenômenos resultam da pura causalidade da matéria de um passado, numa interpretação substancialista da realidade social.

Os temas da ambiguidade da fragmentação-totalização de universos simbólicos nas modernas sociedades urbano-industriais é o que nos tem provocado a refletir sobre as feições do tempo no arranjo das formas de vida social nas grandes cidades brasileiras, tendo em vista que numa tal sociedade os mapas de orientação para a vida social são particularmente ambíguos, tortuosos e contraditórios. Retiramos disso uma importante conclusão para os estudos sobre memória coletiva e patrimônio no mundo contemporâneo: a de que a ambiguidade das experiências de fragmentação-totalização de universos simbólicos não é apenas uma realidade sociológica, mas se configura no interior dos "hábitos-ritmos" (Eckert e Rocha, 2005), por meio dos quais os habitantes das grandes metrópoles vivem seus territórios, compondo, em tais espaços, suas biografias, suas formas de sociabilidade, suas trajetórias sociais, seus itinerários e percursos.

Por um lado, nas cidades moderno-contemporâneas, são inúmeras e distintas as tradições narrativas - por meio das quais se tece a vida urbana - que geram determinados sistemas simbólicos que reúnem seus habitantes em múltiplos territórios de identidade e pertencimento. Por outro, tais identidades e pertencimentos transformam-se ao longo do tempo no interior de um mesmo território. Estamos com isso reforçando a ideia da relevância de uma hermenêutica dos fenômenos sociais que configuram as formas de vida urbana nas cidades brasileiras, irredutíveis a uma razão de ordem econômica, e jamais prisioneiras da cronologia de fatos exteriores (monumentais ou não) à vida vivida por seus habitantes.

\section{O tema da duração e as dinâmicas das formas sociais na cultura contemporânea}

Segundo Georg Simmel, o desafio para a sociologia residiria na construção de um pensamento que conseguisse dar conta das formas de "sociação" através das quais a matéria da vida humana se perpetua e se conserva, sem para isso 
reduzi-las à matéria dos seus conteúdos (língua, hábitos, costumes etc). Para este autor, trata-se de compreender que, aos olhos do cientista social, tais "formas não se reduzem a uma realidade imediata" (Simmel, 1981), ainda que contemplem obras reais e concretas das quais resultam as sociedades e culturas humanas. Esta assertiva nos faz refletir sobre o lugar da representação para a construção do sociológico e do pensamento antropológico, uma vez que tais pensamentos compreendem a vida social por meio das formas pelas quais o ser social se dá a ver, ou seja, por meio de suas figurações.

Mais do que observações de ordem epistemológica - em que Simmel reconhece a forma participando do próprio processo de construção das categorias de análise e interpretação do pensamento antropológico -, interessa resgatar os comentários do autor acerca do fato de as formas de "sociação" carregarem em si mesmas os dilemas da permanência ou não dos grupos humanos no tempo e no espaço. Esses são essenciais, para nós, no que tange à consolidação do campo de pesquisa que foca a cidade como objeto temporal a partir de uma "etnografia da duração" (Eckert e Rocha, 2005). Aderindo a uma "sociologia formista", podemos avançar numa reflexão em torno dos processos de manutenção da identidade do ser social e da sua conservação, ou não, como unidade coletiva, do ponto de vista da transfiguração de uma forma em outra.

Nesse sentido, sustenta Simmel, toda forma (de "sociação") atribui um valor à vida coletiva no transcorrer das suas alterações; a sociedade não está fechada numa duração limitada. Inspirado nesta perspectiva é que Michel Maffesoli propõe o "paradigma estético" (Maffesoli, 1985) como ponto de vista para interpretar os fenômenos sociais, e, nesse sentido, o lugar estratégico da cultura e todo o seu cortejo de símbolos são parte do jogo interpretativo das sociedades humanas. Saímos, assim, da engenharia social para a sociologia como uma forma de arte, ou a um "esteticismo metodológico" como denomina Maffesoli (1985: 35).

Para a epistemologia simmeliana, todo ser é uma mistura de estabilidade e de mobilidade, polaridade entre a vida objetiva e a vida subjetiva. Nessa dialética, se abstrairmos todas as modificações de uma forma de sociação, o que vemos no ser social é tudo aquilo que é duradouro nele; podemos ler na figura do ser a história de sua vida e ver o que constitui sua essência espiritual: o que escutamos de alguém, quando ele fala, é um momento da sua vida em movimento, éo desenrolar de seu ser (Simmel, 1981: 231).

Transladando a perspectiva do formismo simmeliano para o nosso caso da pesquisa antropológica com a etnografia da duração, diríamos que o desafio será, portanto, o de descrever e registrar as leis próprias de tais formas de associação que, sobrepostas e consolidadas, mantêm o ser social nos termos de uma unidade de sentido, dado que a natureza dos fenômenos da cultura não contempla a mesma matéria dos fenômenos físicos. 


\section{A duração das formas sociais e a relevância dos estudos do imaginário}

As reflexões sintetizadas acima nos permitem situar o lugar dos estudos de antropologia da imagem e do imaginário no corpo de uma pesquisa que se proponha a introduzir o fenômeno temporal para a compreensão das dinâmicas da cultura moderno-contemporânea. Em especial, o tema da "consolidação temporal" (Bachelard, 1989b) para o caso dos estudos sobre memória coletiva e patrimônio humano na perspectiva das formas de sociabilidade, das trajetórias e itinerários dos grupos urbanos e de suas narrativas biográficas -é onde, do ponto de vista de uma antropologia urbana, nos situamos.

É ainda com Georg Simmel (1981, Parte II) que adentramos o tema do imaginário no que o autor se refere, ainda que de forma indireta, à força das imagens e seus "processos psíquicos na (con)formação do sentido de unidade para as formas de sociação entre indivíduos". Sob este ângulo, a sociologia simmelianapara nós que estamos interessadas numa etnografia da duração - nos permite pensar o lugar do símbolo constitutivo de toda imagem para a construção da "unidade psicológica" que toda forma de sociação provoca. Obviamente, estamos partindo do que Georg Simmel denomina de "psiquismo coletivo", por meio do qual o ser social se dá a ver como unidade de conjunto. Impossível não associar tal "psiquismo" - que, segundo o autor, permite que a unidade de um grupo seja restituída em tudo o que lhe é desconhecido, por extrapolação, a partir de fragmentos conhecidos (Simmel, 1984: 83) - à dimensão simbólica da imagem e ao seu princípio organizador, que toda forma contempla, no plano da imaginação criadora.

Para atingirmos esse grau de reflexão, nos apoiamos em Gilbert Durand (1984: 25) e no que este autor resgata dos estudos piagetianos da representação. Esses estudos sustentam a ideia de uma "coerência funcional" entre o pensamento simbólico e o sentido conceitual, da qual resulta a unidade e a solidariedade de todas as formas de representação. Com esse procedimento, colocamos em interface o que Georg Simmel (1984: 80) denomina, em seus estudos da filosofia da história, de conteúdos observáveis da forma, com o que Gilbert Durand (1984: 24) denomina de "significação imaginária" da forma, ao tratar da transformação e da mise en forme das sensações pela atividade psíquica.

O que se torna, entretanto, importante reter para o que estamos abordando neste artigo é que em Georg Simmel a figuração da "unidade coletiva" numa forma não representa adesão a um certo tipo de conhecimento sociológico, no qual o papel da imagem seria reduzido ao seu caráter de positividade. Ao contrário, sem vincular a figuração da forma do ser social às amarras do imperialismo do visível e do tangível - ou até mesmo ao dogmatismo das ditas descrições realistas -, o pensamento simmeliano abre espaço para o reconhecimento de que 
a imaginação atribui vida à existência material de uma unidade coletiva, em seu desafio de permanência e continuidade.

Nos termos simmelianos, a passagem de uma forma do social para outra traz à tona a importância da crítica a um certo tipo de individualismo metodológico, nos moldes positivistas, que insiste em enquadrar a vida histórica em dados que lhe são externos, ignorando seus critérios de coerência interna. Isso posto, o conteúdo dos traços observáveis de um fato social ou histórico não determina em si mesmo a unidade de seus traços - e esse é um ponto que nos interessa ressaltar para os estudos da "etnografia da duração"-; o autor conclui que podemos evocar a identidade de um fenômeno mesmo quando observamos nele traços de contradições formais, uma vez que é precisamente o desafio de permanecer igual a si mesmo nas situações mais diversas que faz com que um fenômeno possa criar para si uma unidade (Simmel, 1984: 80).

Nesse ponto, o autor contrapõe-se à doxa cientificista da segregação e classificação de imagens no interior da inteligência lógica do discurso sociológico, ao aderir às estruturas figurativas e às peripécias semânticas que compõem os efeitos de agregação dos quais a vida social é tributária para a interpretação da vida social. A forma acaba por assumir, finalmente, o princípio da diferenciação que introduz a descontinuidade no fluxo contínuo do vivido do corpo social (ao afirmar uma forma, nego outras), visto que nenhuma forma pode ser absolutamente comparável a outra, além de que a afirmação de uma forma eliminaria outras.

\section{A etnografia da duração, o patrimônio e a cidade como objeto temporal}

Os comentários anteriores sobre a obra de Georg Simmel nos permitem, agora, adentrar o tema da duração e suas propriedades em Gaston Bachelard, para falar sobre as cidades moderno-contemporâneas como um "objeto temporal” (Eckert e Rocha, 2005). Atendendo-se à ideia bachelardiana de que o tempo é tanto a hesitação quanto a continuidade substancial da matéria, a qual só intervém tardiamente, a compreensão da dinâmica dos processos culturais nas modernas sociedades complexas, por meio da prática de uma "etnografia da duração" (Eckert e Rocha, 2005), exige do antropólogo sua aderência aos estudos da memória e do patrimônio em outros moldes. ${ }^{3}$

Em nossas pesquisas "no" e "do" mundo urbano contemporâneo, enfocamos as problemáticas tanto do patrimônio quanto da memória como fenômenos que presidem precisamente a esfera dos estudos sobre a consolidação temporal. Isto é, referimo-nos às condições temporais nas quais um corpo social atinge sua perpetuidade como substância "coletiva", em meio às descontinuidades dos 
instantes por ele vividos. Temos consciência de que essa perspectiva rompe com abordagens antropológicas mais convencionais sobre ambos os temas ao reconhecer, em tais fenômenos, a importância singular da vacuidade e da hesitação como matérias conformadoras da tessitura da vida social, tal qual postula Gaston Bachelard, em suas obras Lintuition de l'instant (1932) e La dialéctique de la durée (1989a): a ideia da continuidade do tempo não é um dado em si mesmo, mas "uma obra humana" (Bachelard, 1989a: 51). Através da ideia da continuidade e sucessão temporal no bojo da descontinuidade, em que o tempo revela-se hesitação, a "dialética da duração" bachelardiana nos provoca a ler o patrimônio bem como a memória como integrando as polêmicas descontinuidade/continuidade e fragmentação/universalização nas grandes metrópoles contemporâneas, e em especial nos grandes centros urbanos do Brasil.

Se aceitarmos que tempo é vibração e hesitação, por sua feição lacunar, e se, ao mesmo tempo, concordarmos que a vida é movimento e construção produtiva, criadora de estruturas dinâmicas, toda a interpretação das estruturas espaço-temporais das formas de vida social, nas modernas sociedades urbano-industriais, tem por desafios ultrapassar a perspectiva de uma simples tradução dessa oscilação dos instantes em falhas do tempo. Mais especificamente, etnografando os itinerários dos grupos urbanos e suas formas de sociabilidade, reconhecemos cada vez mais que é o tempo lacunar, (con)figurador das ditas modernas sociedades complexas, aquele que nos provoca a reconhecer, em última instância, a matéria sutil da duração da vida humana num determinado território - as grandes metrópoles.

Para nós, é essa "realidade imediata" do ser social, tensionada de esquecimentos e de lembranças no interior da configuração de suas formas, que tem se oferecido como parâmetro interpretativo para os estudos de uma rythmanalyse 4 das dinâmicas da cultura e suas feições do tempo para a compreensão da vida social nas sociedades complexas. Sob esse ângulo, a realização da "etnografia da duração" traz para a prática da antropologia urbana na contemporaneidade o desafio do estudo da unidade dos traços das grandes metrópoles. Investimos no registro das imagens de conjunto (“coleções etnográficas"), 5 através das quais a vida social se dá a ver nos grandes centros urbano-industriais, para pensar, com elas e por meio delas, as ritmicidades que regulam os arranjos dos tempos vividos e dos tempos pensados, dos tempos subjetivos e dos tempos do mundo em seus territórios. Dos efeitos de agregação dos indivíduos aos efeitos de composição de tais formas sociais no contexto metropolitano, por meio dos recursos audiovisuais na captura das vivências dos habitantes das grandes metrópoles, buscamos compartilhar, com eles, os momentos singulares em que a matéria do tempo, na sinergia entre lembranças e esquecimentos, traduz a vida urbana em raios ondulatórios e em superposições temporais. 
Refletindo sobre a estrutura ondulatória das formas de vida social, cuja regularidade de frequência lhe garante força de existência nas grandes metrópoles contemporâneas, são as narrativas dos habitantes de Porto Alegre/RS que têm nos conduzido a sustentar que, no plano dos jogos da memória, a matéria do ser social se movimenta, ininterruptamente, sem no entanto se dispersar no interior do desacordo rítmico que constitui a própria vida. ${ }^{6}$ Ao se reunir coleções etnográficas de antigas imagens históricas dos acervos da cidade e o registro audiovisual dos itinerários urbanos; das narrativas biográficas e das trajetórias sociais atuais dos seus moradores e a etnografia de rua em seus territórios de vida, estamos procedendo a um ato interpretativo que nos permite observar que matéria das formas de vida urbana, desde suas radiações, reúne, em seu fluxo, passado/ presente/futuro.

Reunindo-se a epistemologia simmeliana à perspectiva da dialética da duração bachelardiana, podemos abordar, então, a cidade como objeto temporal, no sentido de que é somente porque a vida social nas grandes metrópoles contemporâneas atinge sucessivos graus de regularidade rítmica, no interior de um tempo que vibra, e por meio de e no ritmo da imaginação criadora de seus habitantes, que sua forma adquire unidade. Pensar o patrimônio (material ou imaterial, pouco importa) no contexto das sociedades complexas é, nesse ponto de vista, um convite a pensar as formas de vida social que aí transcorrem fora de dogmatismos, os quais têm a pretensão de enquadrar a vida social em categorias tais como desenvolvimento e modernização.

\section{A poeira do tempo, as artes do dizer e as artes do fazer no estudo das formas do social}

Para se aderir à ideia de uma etnografia da duração como parte do desafio de compreender as metrópoles contemporâneas, torna-se necessário para o antropólogo urbano adotar uma verdadeira prudência metodológica, nos termos da poética bachelardiana, no momento de sua adesão a "uma metafísica da poeira" (Bachelard, 1989a). Estamos tratando de uma etnografia sutil aos arranjos das ordenações temporais vividas e representadas pelos habitantes dos grandes centros urbanos. Arranjos concebidos no decorrer da dissolução do tempo, numa série de rupturas, em que a matéria das ações passadas desses habitantes se desenvolve e se manifesta segundo seus distintos universos simbólicos, sob a forma de ritmos, os quais conservam a substância do viver a sua cidade, o seu bairro, a sua rua, o seu edifício.

Nessa dimensão de aproximação da vida social, os habitantes comuns de uma grande cidade tornam-se heróis de suas próprias estórias. A cidade, 
seus bairros, praças e ruas, sob a perspectiva da "festa das palavras" (Sansot, 1986: 46), tornam-se, assim, um desafio ao etnógrafo do mundo urbano-contemporâneo. Nesse ínterim, as obras de Pierre Sansot ${ }^{7}$ nos inspiram a pensar o tema da "etnografia da duração" como parte dos estudos da poética que expressam as "formas sensíveis da vida social", na tentativa de dar prosseguimento à discussão de Georg Simmel "sobre como as formas se mantêm" (1981).

A vida urbana, então (Sansot, 1991: 74; 1990: 60), pode ser compreendida a partir do plano de uma memória coletiva tenaz e perseverante, em que o social se dá a ver para além dos particularismos de classe, de etnias etc. A sedimentação de uma memória coletiva no corpo dessas falas - as falas do "zé ninguém", das "pessoas do povo"-, em sua capacidade de fabular, tem o poder de inventar, nos jogos de sociação que se configuram na ordem do cotidiano, uma fisionomia para ser do social (Rocha, 1994). As "artes de dizer" se associam às "artes de fazer" (De Certeau, 1992), impedindo os laços sociais de cair no esquecimento, e de se dissolver no tempo. A proposta do autor, em convergência com a proposta simmeliana, é a de estudar as realidades sociais tal como elas se apresentam e, se possível, a partir da linguagem através da qual tais realidades sociais se designam no mundo: poéticas das conversações banais do dia-a-dia, numa grande cidade, em sua polifonia e polissemia (Sansot, 1973: 10).

A palavra criadora carrega, assim, a força dinâmica da memória, pois nela se depositam não só as motivações de uma unidade coletiva, mas devaneios, imaginários e recordações, tornando os lugares da cidade espaços afetivos, através dos quais as formas de vida cotidiana encontram formalização, como nos ensina Michel de Certeau e a sua "fala dos passos perdidos" (De Certeau, 1992). Convergindo com essa perspectiva, Pierre Sansot (1973) parte dos postulados da poética da cidade, das artes da conversação e das formas sensíveis de vida social: concebe os jogos performáticos dos gestos, a importância do corpo, da mise-en-scène da vida social para o estudo das vidas das formas a partir da etnografia de sua expressão simbólica no minúsculo, da restauração das práticas sociais e culturais ordinárias de seus habitantes em seus territórios de vida.

Finalmente, desponta para nós o fenômeno da narrativa como pertinente para os estudos da duração, lembrando-nos do que Georg Simmel já comentava sobre a reconstituição dos estados de consciência dos atores históricos - ser e estar - mediados pela formação das imagens subjetivas. Não sendo por isso "coisas" (destacadas de suas raízes), mas fenômenos. Os relatos dos habitantes das grandes cidades sobre as transformações de seus territórios de vida participam, desta forma, dos processos de transposição e simbolização importantes para o estabelecimento da "identidade de essência" entre o eu e o outro (Simmel, 1984: 88). 
Para enfrentar o desafio de compreender as obras da cultura humana reunidas nas grandes metrópoles em constante "criação destrutiva" e "destruição criativa" (Harvey, 1996), Georg Simmel propõe que, ao invés de pensarmos os fenômenos sociais a partir do conteúdo que eles carregam, pensemos as suas formas, pois é através delas que a sociedade se manifesta como um conjunto de ações recíprocas vividas na vida cotidiana. Para o autor não se tratava de pensar a vida social a partir de suas instituições, normas e regras formalistas - a sociedade como fato moral ou escolha racional -, mas como rede de trocas sociais sempre renovadas para além do seu impulso inicial de fundação, num processo incansável de configuração. Para enfrentar o desafio de se trabalhar esta dimensão dos estudos da memória e do patrimônio, sob a lógica da etnografia da duração, torna-se fundamental considerar a decomposição das paisagens urbanas (tratando-se a memória como estudo da temporalidade e não da historicidade) como parte dos arranjos e enquadres da descontinuidade do tempo no coração dos relatos de seus habitantes.

Interpretar as formas implica tratar dos efeitos de agregação que derivam das sociações diversas entre os indivíduos, sendo que a exterioridade da forma traz consigo essa relação dialética sensível entre o presente e o ausente, num percurso em que somente o símbolo pode reunir entre si os seres e as coisas. Nessa perspectiva, ressaltamos os estudos de Gilbert Durand (1984) com quem podemos adensar nossa pesquisa no campo do imaginário, em que toda forma expressa os sentidos que sua figuração evoca.

Mas aqui cabe retomar a ideia de Georg Simmel acerca dos estudos das formas do social para a compreensão do instante em que os processos de sociação emergem. Seguindo a epistemologia simmeliana, podemos pensar, assim, que os laços sociais no interior das grandes metrópoles contemporâneas perseguem os fluxos da experiência vivida de seus habitantes, ganhando formas que persistem para além dos seus conteúdos de origem. É precisamente nesse ponto que retomamos o método formista de Simmel como um convite às reflexões bachelardianas sobre "tempo e duração", no sentido de que ambos, articulados com os estudos de Paul Ricoeur sobre "tempo e narrativa", fornecem importantes chaves interpretativas para a compreensão do fenômeno temporal no interior das modernas sociedades complexas urbano-industriais.

\section{A prática do trabalho de campo e o pluralismo coerente da duração}

Transpondo-se os estudos de Paul Ricoeur (1994) sobre o lugar da narrativa no processo de restauração do tempo para o caso da compreensão dos fenômenos da duração no mundo contemporâneo, podemos avançar no argumento 
sobre a importância dos estudos da forma e do imaginário para a interpretação das modernas sociedades complexas como experiência diegética. Segundo o autor, "o tempo torna-se humano na medida em que está articulado na forma narrativa", sendo no interior dele que as ações dos indivíduos e/ou grupos apresentam-se como "totalidades altamente organizadas" dentro de uma sucessão (Ricoeur, 1994: 15).

Não por acaso selecionamos esse pequeno comentário, em particular, para ressaltar as aproximações da pesquisa antropológica das grandes metrópoles contemporâneas por meio da "etnografia da duração" com os estudos oriundos do campo da narrativa (histórica ou literária). Neste sentido, em outro artigo (Eckert e Rocha, 2003a), pudemos constatar que a experiência do etnógrafo nas grandes metrópoles se traduz no desafio de se integrar às diversas formas espaço-temporais que assumem as "artes de contar" para seus habitantes, enquanto tradição da narrativa etnográfica. Um procedimento de mão dupla que o obriga a refletir, ao mesmo tempo, sobre as diferentes camadas de experiências temporais que deve percorrer o antropólogo (de si e do outro) até a elaboração de sua obra etnográfica (Eckert e Rocha, 2005).

Abrimos, agora, espaço para pensar a narrativa, acoplada aos estudos da duração e do imaginário, como tendo importante papel nos processos simbólicos de enquadramentos espaço-temporais, nos quais toda forma do ser social se torna possível. $\mathrm{O}$ fenômeno da narrativa pode se tornar a chave interpretativa da memória e do patrimônio "no" e "do" mundo urbano contemporâneo, ao nos dar as pistas por meio das quais a forma de um arranjo do ser social se transfigura organicamente em outra, a partir do isomorfismo de seus símbolos convergentes em torno de vastas "constelações de imagens" (Durand, 1984). O que significa dizer, em outras palavras, que a (trans)figuração de uma forma em outra nos mostra a ação recíproca entre os laços de sociação de indivíduos e os seus efeitos de agregação para a estabilidade instável de determinadas estruturas de figuração do ser social nas grandes metrópoles atuais, e os jogos de esquecimento e lembrança que delas decorrem.

Na compreensão da unidade orgânica incompreensível entre ordem e desordem para o caso do mundo urbano contemporâneo, são as narrativas dos habitantes dos grandes centros urbanos industriais que têm nos revelado a interdependência entre as formas e as estruturas dos arranjos sociais, sendo fenômenos que integram os procedimentos de uma "etnografia da duração". Principalmente considerando-se os temas da continuidade e da permanência dos grupos humanos como seres coletivos, na concepção simmeliana, o plano da narrativa nos revela que a forma sociológica que assume a cidade moderna (Simmel, 1979) se apresenta como uma modalidade sui generis de conformação da vida social. Isto é, os grandes centros urbanos apresentam-se não apenas como território em 
que as formas do ser do social se manifestam em suas condições de fugacidade e de efemeridade, seguindo um processo ininterrupto de destruição criativa, mas também um território de enquadramento rítmico de experiências espaço-temporais heterogêneas e díspares.

Sob outro ângulo, "etnografar" a duração diante do fenômeno da destruição criativa nas grandes metrópoles contemporâneas desemboca no desafio da recondução, por parte do etnógrafo, do ser-no-tempo dos indivíduos e/ou grupos por eles pesquisados para além do debate acerca do caráter datável, público e documentado dos tempos por eles vividos. Ou seja, implica considerar, em suas preocupações etnográficas, as preocupações ordinárias dos habitantes das grandes cidades, na ordem do vivido, para atingir a capacidade de "contar" suas estórias com a ajuda desse tempo.

Em especial, do ponto de vista do etnógrafo, a experiência diegética representa, para a realização da etnografia da duração, compreender a passagem do espaço figurado da narrativa documental - isto é, os dados etnográficos colhidos no registro das trajetórias sociais, dos itinerários urbanos e das narrativas biográficas dos seus habitantes -, para o espaço de representação da narrativa etnográfica, tendo em vista, nas palavras de Paul Ricoeur (1994), a "tríplice mímese" por meio da qual fazemos concordar tudo aquilo que no tempo se apresenta como discordância. Transladando os comentários do autor para os cânones da tradição da antropologia urbana, diríamos que o fenômeno da duração recoloca os estudos de narrativa como parte integrante da pesquisa etnográfica nas modernas sociedades contemporâneas. Ou seja, dar conta da "tríplice mímese" abarcaria: a mímese (1), isto é, da pré-figuração, referida à experiência temporal imediata vivida pelos indivíduos (sujeitos da pesquisa), e que precede o relato etnográfico; a mímese (2), da configuração, situada na experiência temporal da tessitura da narrativa etnográfica propriamente dita, e a mímese (3), da reconfiguração, isto é, da experiência temporal que sucede a obra etnográfica, e sob a qual nem o etnógrafo, nem os sujeitos de sua pesquisa podem responder por ela integralmente.

Nos moldes de uma etnografia da duração, isso significa explorar inúmeros dispositivos de "domesticação" simbólica do tempo como modalidade de enquadramento do ser do social no teatro da vida urbana. Estão em jogo, de um lado, as motivações simbólicas do etnógrafo em sua experiência temporal nos territórios da vida urbana; por outro, os dispositivos simbólicos evocados pelos indivíduos e/ou grupos ao longo dos relatos de suas vidas vividas, na origem das quais está toda a razão de ser da obra etnográfica (considerando-se, evidentemente, as discordâncias do tempo no relato dos próprios sujeitos de pesquisa). É importante ressaltar que, em tal contexto hermenêutico, $o$ ato de narrar exige, da parte do etnógrafo, o domínio das motivações simbólicas de controle do tempo 
tanto por parte do outro quanto de si, se considerado o tempo como um fenômeno granular e cumulativo, que não pode prescindir da narrativa para se consolidar.

Neste ponto, é notável que Georg Simmel (1979) reconheça nas descontinuidades das formas de vida social na cidade moderna uma adjudicação de sentido para a configuração do seu corpo coletivo. Podemos, portanto, interpretar que é na contingência da fuga do tempo que a matéria dos laços sociais se eterniza. Nos termos de Simmel, diríamos que é através de uma constante reconciliação entre uma cultura objetiva e uma cultura subjetiva que o viver humano constrói para si uma unidade - uma reconciliação que se dá a ver no tempo e no espaço, e que podemos descrever no interior da vida metropolitana. Aliando-se a epistemologia simmeliana à fenomenologia bachelardiana da duração e aos estudos durandianos do imaginário - e estes, por sua vez, aos estudos da narrativa em Paul Ricoeur (1994) - para o desenvolvimento da pesquisa sobre o fenômeno da duração em sociedades complexas, vamos novamente encontrar, sob o ângulo da intriga, o reconhecimento do caráter granular e descontínuo que abarca toda a experiência humana do tempo e suas exigências de enquadramento pela via do muthos.

Com Paul Ricoeur (1994) reconhecemos que uma ação humana só pode ser narrada porque ela se encontra, desde suas origens, articulada em signos, regras, normas; desde sempre "simbolicamente mediatizada". E retornamos aqui às mesmas constatações de Georg Simmel (1984) para o caso das suas inquietações em torno da duração das formas do ser social, isto é, da identidade entre o “eu” e o "não-eu”. Prosseguindo, com Paul Ricoeur (1994) reconhecemos que toda ação narrada refere-se, ao menos, a dois movimentos distintos, ao que "de fato aconteceu" e a tudo aquilo que é da ordem da interpretação - o que converge com a ideia bachelardiana das diferenças entre o "tempo pensado e o tempo do mundo" para o caso dos seus estudos da consolidação temporal (Bachelard, 1989a). Finalmente, ainda com os estudos de Paul Ricoeur (1994) sobre a tessitura da intriga para o fenômeno da experiência temporal na forma narrativa, podemos observar que toda narração contempla uma ordenação temporal determinada - convergindo para o estudo durandiano das estruturas antropológicas do imaginário e das suas modalidades simbólicas de controle do tempo (Durand, 1984).

Sob esse ângulo, a pesquisa com antropologia urbana no contexto das sociedades complexas não pode prescindir do estudo do imaginário, da imaginação e da inteligência coletiva de sua comunidade, que a faz contínua a partir de seu interior descontínuo. A compreensão da "duração" naquilo que se transforma, tanto quanto o mutável no corpo de uma duração, permite ao antropólogo, pesquisando a memória coletiva e o patrimônio etnológico de uma grande me- 
trópole, adentrar os diversos territórios onde a vida social se processa, abdicando de submetê-la a uma razão instrumental, para aderir à sua causalidade formal. Trata-se, assim, de ultrapassar todo o dogmatismo que se apoia na minimização da força do sensível na tessitura das formas de organização da vida urbana, para poder ver uma forma perdurar - no interior de suas transfigurações - de uma maneira aparentemente aleatória em outra.

$\mathrm{Na}$ contemporaneidade, a decomposição de prédios, a destruição de ruas, a mutação da paisagem de um bairro, enquanto experiências dramáticas para os habitantes de uma grande cidade, conservam a possibilidade do relato, da história, revelando-se uma situação de conhecimento em ação, a ser reconhecido e interpretado. Se a memória de uma cidade é, por um lado, monumental, por outro, ela é vivida no percurso cotidiano das ruas e praças. Resgatar os itinerários dessas memórias como espaços de encenações da vida coletiva de um grande centro urbano significa colocá-los no bojo da própria gênese do seu patrimônio etnológico.

Sob esse ponto de vista, os grandes centros urbanos tornam-se, assim, um mundo tecido a partir dos laços simbólicos de seus habitantes. Laços urdidos tanto pelos atos de consciência de seus moradores, segundo suas distintas tradições, quanto pela consciência homogeneizadora das temporalidades históricas e progressistas. Mas, acima de tudo, laços desde o caráter simbólico das ações sociais, que nos conduzem à aceitação do papel fundamental da vida dos símbolos na construção das cidades moderno-contemporâneas como espaço de atualização de utopias e distopias e, em decorrência, da importância dos mitos na configuração da vida cotidiana de suas comunidades urbanas.

\section{O viver a cidade como experiência diegética narrada}

Neste artigo, advogamos que todo o esforço interpretativo das modernas metrópoles contemporâneas transparece no ato de se restaurar (através das imagens fotográficas, videográficas, literárias e sonoras) as memórias narradas de uma cidade, não apenas pela voz de seus habitantes, mas também pelos quadros sociais em que se depositam seus acervos, seus museus, seus álbuns etc.

A proposta é a exploração dos "cenários da memória" dos habitantes da cidade como condição que integra as ações e gestos de preservação patrimonial de seus territórios, alertando-se para a importância do ato compreensivo da experiência mnésica e fabulatória dos grupos urbanos em itinerância para se pensar a construção de suas alteridades na vida coletiva nas grandes aglomerações do país. No ato de narração se enraíza o desafio da prática da etnografia da duração, que abarca o ato de compartilhar com o próprio narrador - habitante das ci- 
dades - os jogos de esquecimento e lembrança dos fatos, dos acontecimentos e dos instantes por ele vividos nos seus territórios. $\mathrm{O}$ processo de morte e renascimento de uma cidade, os ritos de destruição e reconstrução, o suplício de sua matéria terrestre são assim um campo fértil de análise das representações simbólicas acerca do tempo no mundo urbano contemporâneo. Retornando ao tema da fenomenologia bachelardiana do tempo, trata-se aqui de um ato de pensar em tripla potência (pensar um pensamento que se apresenta pensando as intensidades descontínuas dos instantes).

Por essa razão, a "etnografia da duração" não consiste em uma etnografia da lembrança-vestígio dos dados imediatos da consciência dos moradores de um grande centro urbano em contínua construção/destruição/deformação. Antes, pelo contrário, se afirma como um ato de conhecer mediado pela fabulação, tanto por parte do etnógrafo, quanto por parte dos seus sujeitos de pesquisa, o que faz com que cada episódio banal evocado por eles em presença do etnógrafo se propague, em seu registro documental, como matéria viva das tradições da cidade: 0 estudo da "etnografia da duração" aceita como suposto que a matéria das lembranças ou reminiscências de um tempo vivido adquire uma substância somente se ela se "temporaliza" sob a forma de ondulações do próprio ato que encerra o "tempo pensado" (Bachelard, 1989).

O percurso intelectual traçado acima resulta no reconhecimento da "gênese recíproca", (Durand, 1984) no plano do imaginário, que faz toda a forma do ser oscilar da construção de uma duração, em sua luta contra a matéria perecível do tempo, à sua completa dissolução e morte, e vice-versa. Inserimos, por esta via, numa alusão ao conceito de "trajeto antropológico" em Gilbert Durand (1984: 24), as preocupações simmelianas com a manutenção das formas sociais no campo dos estudos do imaginário. Nessa perspectiva, a pesquisa etnográfica da memória coletiva e do patrimônio no contexto das sociedades complexas remete a pensar o trajeto antropológico de tais formas de sociação, reconhecendo-se a anterioridade "tanto cronológica quanto ontológica" (Durand, 1984:24) dos símbolos por meio dos quais o ser social atinge uma duração.

Isso posto, para finalizarmos nossas reflexões sobre a "etnografia da duração", seu "paradigma estético" e os estudos da forma e do imaginário, temos que retomar brevemente a fenomenologia bachelardiana para situar o que aqui estamos denominando de "experiência diegética" para a pesquisa em sociedades complexas. O uso do termo "diegético" (oriundo dos estudos de narrativa) em contrapartida ao de mímese (anteriormente empregado) para abordar a compreensão da duração no mundo urbano contemporâneo não é casual. Empregar o termo diegése para ressaltar o tempo da trama (tempo pensado), em relação ao tempo real (tempo do mundo), que constrange a ritmicidade da vida vivida pelos moradores nas grandes metrópoles, é simplesmente um recurso empregado para 
se reforçar a ideia da cidade moderna como lugar de fabulação de múltiplas narrativas por parte de seus habitantes.

Em especial, pensar as cidades a partir da perspectiva do conjunto de acontecimentos narrados numa determinada dimensão espaço-temporal nos incita a retomar a poética do devaneio (Bachelard, 1993), enlaçando-a à poética do espaço (Bachelard, 1989b), para projetá-las diretamente no interior de uma dialética da duração (Bachelard, 1989a). A intenção é a de interpretar a experiência espaço-temporal que compreende a matéria a partir da qual se configuram as grandes metrópoles contemporâneas. Nos termos de uma "etnografia da duração", a nossa tentativa é sensibilizar o antropólogo em seu trabalho de campo para a ação fabulatória dos jogos da memória de seus habitantes e de sua própria memória.

Vamos encerrar nossa argumentação retornando à afirmação da significação imaginária que configura toda a forma do ser social, atribuindo-lhe uma unidade onde se corre o risco da descontinuidade. Nesse sentido, poderíamos pensar que, se em termos simmelianos a vida social é forma tributária dos "efeitos de agregação" dos laços de sociação dos habitantes entre si, em determinados territórios, valendo-nos dos estudos de Pierre Sansot sobre a poética das cidades, tal "agregação" não ocorreria ao acaso, mas segundo "certas zonas matriciais", na congruência de símbolos estruturados em termos de uma forma-forte. "Etnografar" tais formas de agregação e seus arranjos representaria o desafio interpretativo do antropólogo de atuar numa "recoleção" de sentidos com a intenção de interpretar seus espaços de vida coletiva.

Pensar a noção de forma sociológica como reunião do inteligível e do sensível, para o estudo da duração no mundo urbano contemporâneo, exige tratar das figurações de tais "efeitos de agregação" a partir da perspectiva do "dinamismo transformador", que é inerente a tais formas (suas estruturas), pelo fato de configurar como parte das figurações do imaginário (Simmel, 1981, 1984). Se Georg Simmel (1998), em seus estudos sobre Roma, Florença e Veneza, admite que é por intermédio da forma que o "espírito se torna visível" (e ele alude, sem dúvida, às comunidades urbanas que habitaram, e habitam, estas cidades), para a epistemologia bachelardiana é o onirismo intelectual que permite a condição da integridade do conhecimento da duração como consolidação de estruturas espaço-temporais diversas. $\mathrm{O}$ pensamento que discorre sobre a forma de uma duração (a qual por sua vez se expressa num pensamento que reflete sobre si mesmo), portanto, é conhecimento, ao mesmo tempo, de si e do mundo (Bachelard, 1993).

Apoiando-nos nos fundamentos do novo espírito antropológico durandiano, insistimos neste ponto. Isto é, em que as formas do social nas modernas sociedades complexas podem ser pensadas através de sua convergência em torno 
de múltiplos núcleos de sentido, e segundo a classificação dos símbolos por elas constelados. Tal convergência opera através das homologias ("equivalências morfológicas"). Novamente, a "forma" aqui retornaria ao centro do nosso argumento, ou seja, do valor estético dos elementos que ordena o fenômeno da duração nas grandes metrópoles contemporâneas - "obra criada para responder a todas as finalidades da vida humana" (Simmel, 1998).

Entretanto, eufemizando a eterna agonia da matéria terrestre, nas grandes cidades, são os moradores aqueles que são capazes de recriar regras de ação e novas condutas para enfrentar as situações propostas por um ambiente urbano em constante mutação. A operação de "reconstituição do passado" de uma cidade é, portanto, um processo ontológico que remonta às fontes arqueológicas do nascimento de uma comunidade urbana, pois, por esta operação, seu corpo social coloca em jogo, através de um dispositivo simbólico, o desafio de sua inserção espaço-temporal no mundo.

Sem dúvida, essa perspectiva de "etnografar" o ato de viver o tempo no mundo urbano contemporâneo, aderindo ao ritmo de sua própria matéria ondulatória, choca-se com o processo de construção e demarcação de uma nova temporalidade e épistémè, do qual muitos de nós, antropólogos, para o pior ou o melhor, somos herdeiros bastardos. Ou seja, da épistémè clássica, responsável pela "desfiguração da visão do homem" (Simmel, 1998: 12) no Ocidente judeu-cristão e pela gênese da concepção de pessoa moderna pela via da dessacralização do fenômeno da memória. Nesse sentido, pensar as modernas sociedades contemporâneas é refletir sobre as grandes metrópoles como fenômenos presididos por condições temporais específicas através das quais um corpo coletivo atinge sua perpetuidade como substância em meio às descontinuidades de instantes por ele vividos.

Notas

1. Ver por exemplo, Durham (1984, 2004) e Cardoso (1986).

2. Além desse autor, sugere-se a leitura de outros antropólogos que seguem a linha de pesquisa inaugurada por Ruth Cardoso e Eunice R. Durham. Entre eles: Caldeira (2001), Magnani \& Torres (2000) e Oliven (1974, 1993).
3. Partimos aqui de artigos produzidos no sentido de problematizar a dimensão bergsoniana do tempo e suas influências na obra de Maurice Halbwbachs (1920, 1925, 1950).

4. "A ritmanálise procura em toda parte ocasiões para ritmos (...). Ela nos previne assim sobre o perigo que há em viver no contratempo, desconhecendo a 
necessidade fundamental das dialéticas temporais" (Bachelard, 1963: 133).

5. Projeto de pesquisa CNPq de Ana Luiza Carvalho da Rocha, 1997-2008.

\section{Referências bibliográficas}

BACHELARD, Gaston. 1932. Lintuition de l'instant. Paris: Gonthier.

1940. La formation de l'esprit scientifique. Paris: J. Vrin.

\section{Paris: Puf.}

1989b. La poétique de l'espace.

Paris: Puf.

Paris: Puf.

Benjamin, Walter. 1989. Walter Benjamin:

Obras escolhidas. Vol. 3. São Paulo:

Brasiliense.

BERGSON, Henri. 1959. Lévolution créatrice. Paris: Puf.

1969. Matiére et mémoire. Essai sur la relation du corps à l'esprit. Paris: Puf.

1970. Essai sur les données immédiates de la conscience. Paris: Puf.

CALDEIRA, Teresa. 2001. Cidade de muros. São Paulo: Edusp.

CARDOSO de OLIVEIRA, Roberto. 2000. O trabalho do antropólogo. São Paulo: Unesp.

CARDOSO, Ruth. 1986. A aventura antropológica. São Paulo: Paz e Terra.

DE CERTEAU, Michel. 1992. A invenção do cotidiano. Petrópolis: Vozes.

DURHAM, Eunice. 1984. A caminho da cidade. São Paulo: Perspectiva.
6. Novamente a referência são os comentários de Bachelard (1989: 130-135), em que o autor se refere às relações entre a matéria e o tempo.

7. Cf. Sansot (1986, 1992, 1997, 2003).
Paulo: Cosac \& Naify.
DURAND, Gilbert. 1984. Les structures anthropologiques de l'imaginaire. Paris: Dunod.
. 1992. Limagination symbolique. Paris: Puf.
ECKERT, Cornelia; ROCHA, Ana Luiza Carvalho da. 2002. Prémisses pour une étude de la mémoire collective dans le monde contemporain sous l'optique des itinéraires des groupes urbains brésiliens. Sociétés, Revue des Sciences Humaines et Sociales, Demeures de l'Humain, Paris, France, DeBoeck Université, vol. 75.

- 2003a. O antropólogo na figura do narrador. Habitus, Goiânia, UCG, vol. 1, n. 2, jul./dez.

- 2003b. Etnografia de rua: estudo de antropologia urbana. Revista Rua, Campinas, Unicamp, vol. 9, p. 101-127.

-2005. O tempo e a cidade. Porto Alegre: EdUFRGS.
- 2007. A memória como espaço fantástico. In: GUIGOU, Nicolas (org). Trayetos antropologicos. $1^{\mathrm{a}} \mathrm{ed}$. Montevideo: Nordan-Comunidad, p. 33-42.

FREUND, Julien. 1992. De Max Weber à Georg Simmel. Revue Sociétés, Paris, Dunod, n. 37, p. 217-224. 
HALWBACHS, Maurice. 1925. Les cadres sociaux de la mémoire. Paris: Félix Alcan.

1950. La mémoire collective.

Paris: Puf.

HARVEY, David. 1996. Condição pós-moderna. São Paulo: Loyola.

MAFFESOLI, Michel. 1979. La conquête $d u$ présent. Paris: Puf.

-1985. La connaissance ordinaire, précis de sociologie compréhensive. Paris: Méridiens.

Paris: Plon.

1990. Aux creux des apparences.

1992. La transfiguration $d u$ politique, Paris: Grasset.

MAGNANI, José G. \& TORRES, Lilian (org). 2000. Na metrópole. São Paulo: Edusp/Fapesp.

MINCK, Louis. 1968. The autonomy of historical understanding. Review of Metaphysics 20, p. 667-698.

OLIVEN, Ruben. 1974. O metabolismo social da cidade. Porto Alegre, EdUFRGS.

- 1993. A parte e o todo, Petrópolis: Vozes.

RICOEUR, Paul. 1994. Tempo e narrativa. Vol. 1. São Paulo: Papirus.

ROCHA, Ana Luiza Carvalho da. 1994. Le sanctuaire du désordre. L'art de savoir-vivre des tendres barbares sous les Tristes Tropique. Une étude sur l'esthétique urbaine et la mémoire collective au sud du Brésil. Tese (Doutorado), Université Paris V, Sorbonne, Paris.

SANSOT, Pierre. 1983. Variations paisagères. Paris: Klincksieck. 1986. Les formes sensibles de la vie sociale. Paris: Puf. 1992. Les gens de peu. Paris: Puf. 1997. Poétique de la ville. Paris : Klinckieck. 2003. Le goû de la converstion. Paris: Desclée de Brouwer.

SIMMEL, Georg. 1934. Cultura femenina y otros ensayos. Madrid, Revista de Occidente. 1979. A metrópole e a vida mental. In: VELHO, Otávio (org). Sociologia urbana. Rio de Janeiro: Zahar.

-1981. Sociologie et épistemologie. Paris: Puf.

- 1984. Les problèmes de la philosophie de l'histoire. Paris: Puf.

- 1998. Rome, Florence, Venice. Paris: Allia.

VELHO, Gilberto. 1973. Utopia urbana. Rio de Janeiro: Jorge Zahar. . 1981. Individualismo e cultura. Petrópolis: Zahar.

\section{Resumo}

Nosso objetivo neste artigo é investir no estudo da memória coletiva no mundo urbano como resultado da ação recíproca de indivíduos e de grupos. Destacamos a importância das formas específicas dos arranjos da vida social segundo a complexidade e dinâmica da vida moderna de seus habitantes. Propomos uma etnografia da duração, para tratar do tempo e da memória no âmbito do campo antropológico. Trata-se de aprofundar a compreensão do processo de territorialização/desterritorialização de identidades sociais no 
mundo contemporâneo. Sugere-se a noção de ritmo como démarche para o conhecimento do movimento da descontinuidade/continuidade como sistema de valores acionados por tais grupos e de suas formas de sociabilidade no contexto citadino.

Palavras-chave: memória coletiva, etnografia, sociabilidade, vida urbana, cidade, imagem, tempo

\section{Abstract}

This article studies the collective memory in the urban world as a result of the action of individuals and groups, showing the importance of the specific forms of social life arrangements according to the complexity and dynamics of the modern life of its inhabitants. It proposes an ethnography of duration to deal with time and memory in the anthropological field. The idea is to deepen the comprehension of the process of rooting/derooting of social identities in contemporary world. It also suggests the notion of rhythm as a way to know the movement of continuity/descontinuity as a system of value used by those groups and to understand their sociability forms in the city context.

Key words: collective memory, ethnography, sociability, urban life, city, image, time

\section{Résumé}

Notre but dans cet article concerne l'étude de la mémoire collective dans le monde urbain étant donnée l'action reciproque des individus et des groupes. Nous mettons en relief l'importance des formes spécifiques des arrangements de la vie sociale selon la complexité et la dynamique de la vie moderne de ses habitants. Nous proposons la réalisation d'une ethnographie de la duration pour traiter du temps et de la mémoire dans le champs de l'anthropologie. Nous cherchons à compreendre le processus de territorialisation/ desterritorialisation des identités sociales dans le monde contemporain tout en signalant la connaissance du contexte de la descontinuité/continuité et le système des valeurs accioné par des groupes dans les formes de sociabilité dans le contexte urbain.

Mots-clés: mémoire collective, ethnographie, sociabilité, vie urbaine, ville, image, temps 